\title{
Capítulo 4. \\ Factores que contribuyen a una antropología del cuidado
}

parte de la alteridad, el tiempo y el pensamiento, existen otros 1 factores que ayudan a cimentar una propuesta antropológica centrada en el cuidado, como la actividad física, el manejo adecuado de las emociones y una buena alimentación. Cabe aclarar que estos nuevos factores no riñen con los primeros, sino que, por el contrario, contribuyen con el desarrollo de los mismos, resultando indispensables el reconocimiento de los otros, el tiempo, y el ejercicio de procesos reflexivos serios y concienzudos. Es idea central de este capítulo seguir enriqueciendo la discusión en torno a los componentes que pueden contribuir a edificar una plataforma teórica, que enriquezca la concepción antropológica que tieneel cuidado como eje central de preocupación.

En una sociedad cada vez más enferma, donde el sedentarismo ha llegado a niveles exagerados y el estrés es la constante en las personas, los riesgos para la salud han aumentado notablemente. Adicionalmente, no tenemos tiempo para cuidarnos, puesto que debemos recorrer muchas veces grandes distancias para llegar a los lugares de trabajo, y el poco tiempo sobrante ha sido raptado por la tecnología; vivimos pobres de tiempo, y sin tiempo no podemos dedicarnos al cuidado de nosotros, ni al cuidado de nuestros compañeros de camino, según lo reconoce el investigador Sánchez Bañuelos: 
El fenómeno del creciente y excesivo sedentarismo de la población que se ha venido produciendo en las sociedades avanzadas contemporáneas, constituye un serio motivo de preocupación para la salud pública, ya que la inactividad física prolongada es uno de los factores de riesgo más importantes respecto a las enfermedades cardiovasculares, una circunstancia que puede servir de mediación para el desarrollo de otras enfermedades de índole muy diversa, y es la causa de un deterioro progresivo más rápido y prematuro en el individuo. (Sánchez Bañuelos, 1996, p. 15)

Sin embargo, no solo las enfermedades cardiovasculares nos acechan, sino que también nos están asediando las enfermedades respiratorias, infectocontagiosas, los diferentes tipos de cáncer y muchos de ellos, derivados de la falta de hábitos para realizar alguna actividad física, a sabiendas de que un ethos de vida saludable, se puede cultivar gracias al ejercicio constante. De esta manera, a la par con la actividad física, es necesario desarrollar otros tres factores idóneos a la hora de cultivarnos físicamente y prevenir dolencias futuras, estos son una alimentación adecuada, unas pautas de descanso habituales y de conveniente duración, y el consumo de agua potable abundante.

Ahora bien, al encontrarnos inmersos en una sociedad que no tiene descanso a causa de la era de las velocidades, se torna difícil alimentarse adecuadamente y procurar realizar alguna actividad fisica, pues se carece de tiempo. Adicionalmente, se come a la ligera, se consumen embutidos y muchas bebidas azucaradas, a la vez que gran cantidad de comida "chatarra" que en lugar de alimentar causa alteraciones en la salud. Inversamente, se consumen pocas frutas, casi nada de verduras y muchas carnes rojas; hábitos que terminan causando enfermedades gastrointestinales que afectan otros sistemas del cuerpo, como el inmunológico.

Adicionalmente, acumulamos trabajo y preocupaciones por el desarrollo del mismo, a tal punto que nos vemos abocados a dormir poco, y muchas veces no tenemos un sueño de calidad por 
estar preocupados por los compromisos laborales, según lo expresa Sánchez Bañuelos: “... existe un nivel de estrés que tiene que soportar el individuo, que deteriora la calidad de vida y se incrementa la posibilidad de que se produzca un deterioro de la salud" (Sánchez Bañuelos, 1996, p. 24).

Es un fenómeno casi común encontrar gente cansada a toda hora, y con una especie de síndrome de agotamiento y de poco cuidado de sí, pues no faltan las personas que cuando tienen un tiempo libre, en vez de cuidarse, se desfogan y aprovechan para consumir sustancias que coadyuvan en el deterioro paulatino de la salud, como el consumo de tabaco y de alcohol, comer en exceso, seguir dietas extremas e inadecuadas, o conducir en forma exagerada por el afán de llegar a tiempo al lugar de trabajo. Frente a estos desmanes, la profesora Cruz Molina nos recuerda que muchas de las enfermedades pueden ser evitadas implementando acciones educativas, encaminadas al cuidado:

Según se ha evidenciado en estudios epidemiológicos, en los países desarrollados la salud está determinada fundamentalmente por los estilos de vida y del medio ambiente. En consecuencia, la mayoría de problemas de salud son susceptibles de ser evitados o paliados mediante acciones educativas, además de sanitarias. Por ello, la prevención continúa siendo un reto y la promoción de la salud un conjunto de estrategias necesarias para mejorar la salud y la calidad de vida de todas las personas. (Cruz Molina, 2003, p. 17)

Como lo señala Cruz Molina, resulta muy importante emprender acciones de promoción de la salud, donde se puedan evitar enfermedades tomando conciencia de lo que consumimos, y de cómo lo consumimos, enfatizando más en la prevención que en la curación frente a las enfermedades. 


\section{La actividad física: factor esencial en nuestro cuidado}

Uno de los elementos indispensables para el cuidado de la salud es la constancia en el ejercicio físico, elemento que a través del tiempo ha sido reconocido según la expresión del adagio latino "mente sana en cuerpo sano".

El cuerpo humano ha evolucionado para ser físicamente activo. En otras palabras, nuestro cuerpo necesita la actividad fisica para mantenerse sano. A lo largo de la historia, la supervivencia de la especie humana ha dependido de la caza o de la recolección de alimentos, ocupaciones que exigían una actividad física prolongada e intensa. (Aznar Laín, s. f., p. 7)

La existencia moderna con sus artilugios tecnológicos ha promovido un estilo de vida sedentario, que ha hecho gradualmente que los individuos no se ejerciten y estén con sobrepeso u obesidad mórbida, que a su vez se convierte en caldo de cultivo de enfermedades de diferente índole, como las de origen cardiovascular, que cada vez más asesinan silenciosamente a millones de personas en el mundo.

La inactividad física ha dado muerte a mucha más gente que todas las guerras actuales en el mundo. Según Aznar Laín, el cuerpo está diseñado para moverse, y es hora de tomar conciencia de la importancia de ello. Si el cuerpo está enfermo, obviamente, la parte psíquica del ser humano estará bloqueada igualmente, por lo que debemos mantenernos en óptimas condiciones físicas para poder desempeñar a cabalidad nuestras actividades intelectuales, recreativas e interpersonales.

La falta de actividad física inicia desde la infancia, con los nuevos modelos de vida que se han promovido con el acceso a las nuevas tecnologías de la información y de la comunicación. 
En los tiempos de antaño, los niños consagraban gran parte de su tiempo a practicar actividades al aire libre, quemando calorías, expulsando toxinas por el sudor y ejercitando sus músculos y sus articulaciones; cosa que, en muchos, ha pasado a segundo plano a causa de la aparición de la televisión, el auge de los videojuegos, la eclosión del internet y la masificación de los móviles. De hecho, en los colegios, hace veinte años la educación física era una actividad placentera, cosa que en la actualidad se ha tornado para muchos niños y adolescentes en algo aburridor que debería dar paso a otras actividades "más útiles" para la vida. Frente a esto urge enfatizar en la importancia de realizar alguna actividad que implique movernos, para que, de esa manera, se pueda combatir el sedentarismo, el cual constituye una de las mayores causas de muerte en nuestro hemisferio.

Adicionalmente, a la vida sedentaria se le han sumado otros factores que contribuyen al deterioro de nuestra salud. Nótese que cada vez más aparecen alimentos de un alto contenido calórico y energético, como las comidas rápidas y las bebidas azucaradas que son de fácil acceso y de alta promoción publicitaria. $\mathrm{Al}$ respecto, no solo se debe combatir la vida sedentaria, sino concientizarnos sobre el peligro que conlleva para la salud el hecho de consumir alimentos nocivos y altamente tóxicos.

Entre las actividades fisicas cabe destacar las cardiovasculares, las de fuerza/resistencia muscular y las de flexibilidad.

\section{-Actividades cardiovasculares}

Estas actividades también reciben el nombre de actividades "cardiorrespiratorias" o "aeróbicas", porque exigen que el cuerpo transporte oxígeno utilizando el corazón y los pulmones. Existen varias actividades dentro de este conjunto que vale la pena mencionar por hacer parte de la vida cotidiana, como planchar ropa, limpiar la casa, pasear por el campo, caminar por la ciudad, pintar, 
jugar deportes como bádminton, montar bicicleta, nadar, trotar (fotografia 5), correr y bailar, entre otros.

Estas actividades fortalecen el corazón, los pulmones, los músculos y los huesos. Se trata de actividades que vale la pena ejercitar, a la vez que son agradables y despejan la mente y el corazón.

Fotografía 5. El trote como actividad física saludable

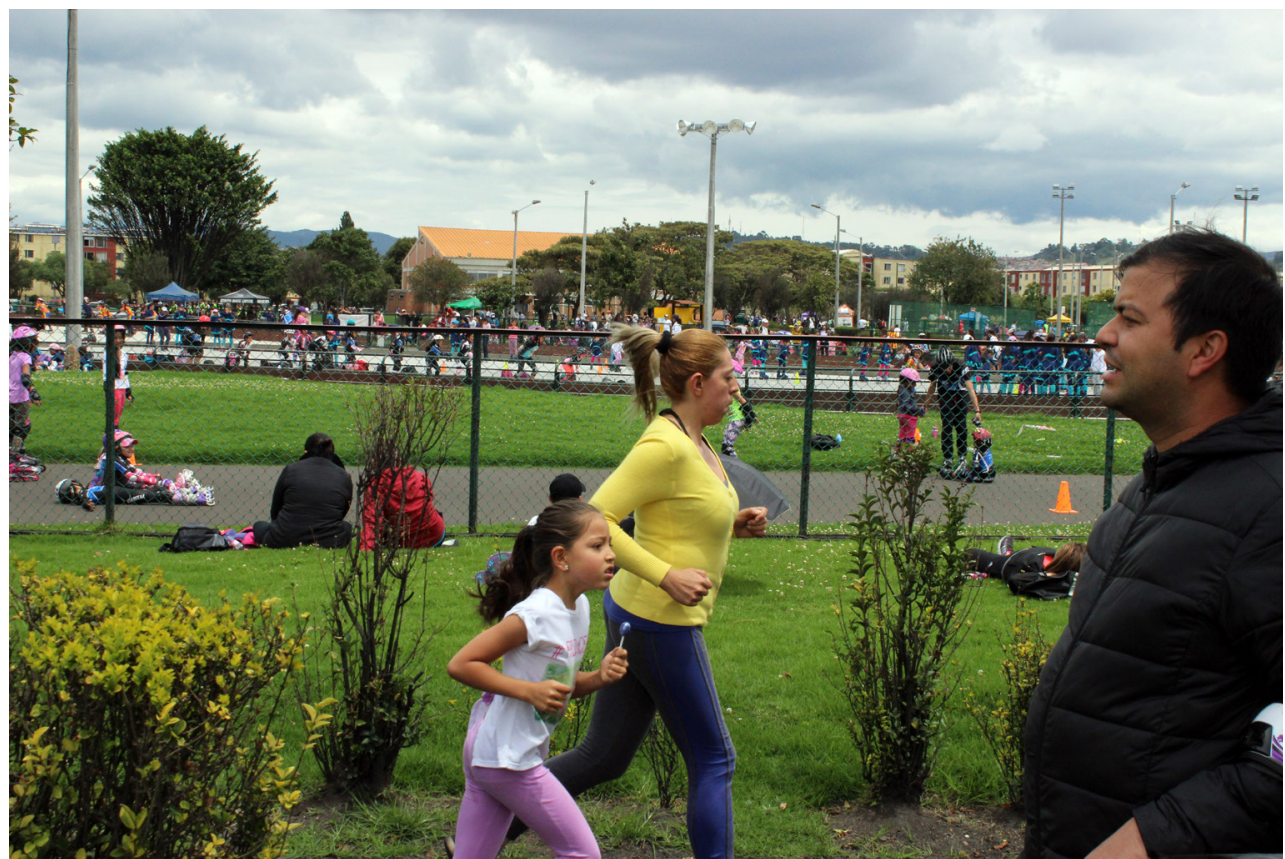

Como lo muestra la foto, se recomienda caminar o trotar durante media hora diaria para quemar los excesos de calorías y fortalecer los músculos y los huesos.

Fuente: archivo del autor.

\section{-Actividades de fuerza y resistencia muscular}

La fuerza muscular es la capacidad del músculo para generar tensión y superar una fuerza contraria. La resistencia muscular es la capacidad del músculo para mantener su tensión y sus 
contracciones durante un período prolongado de tiempo. Estas actividades sirven para desarrollar y fortalecer los músculos y los huesos (Aznar Laín \& Webster, s. f., p. 17).

Entre las actividades de fuerza y de resistencia muscular que podemos practicar cabe mencionar las siguientes: saltar lazo, escalar muros o montañas, hacer lagartijas, jugar a las carretillas, lanzar el balón, pedalear en una canoa, remar, levantar pesas, transportar objetos pesados, algunas de estas actividades se pueden desarrollar al aire libre, como lo muestra la fotografia 6.

Fotografia 6. Actividades de fuerza y resistencia muscular

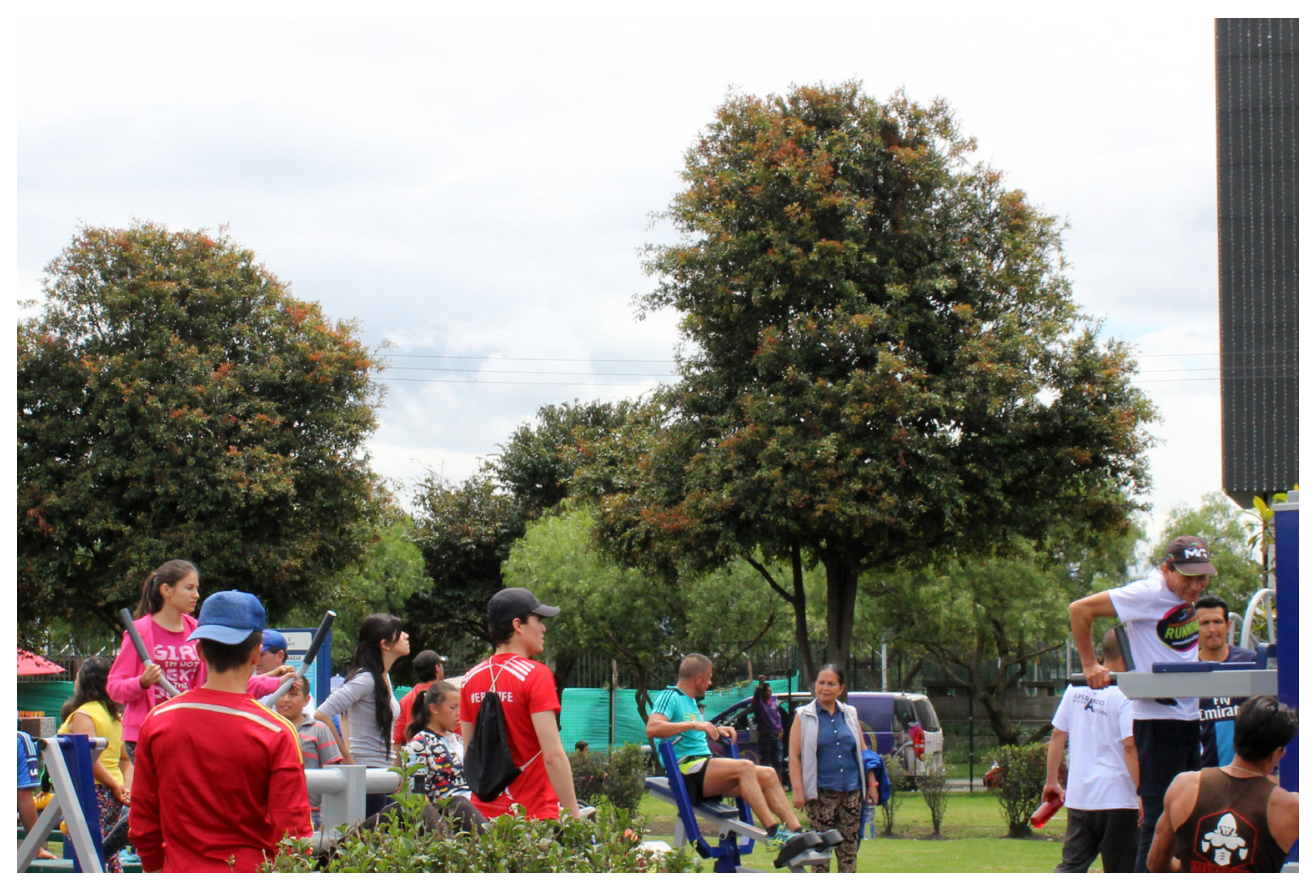

Fuente: archivo del autor. 


\section{-Actividades de flexibilidad}

La flexibilidad es la capacidad de las articulaciones para moverse en todo su rango de movimiento. La flexibilidad tiene un carácter específico para partes concretas del cuerpo y está en función del tipo de articulación o articulaciones implicadas, de la elasticidad de los músculos y del tejido conectivo (por ejemplo, los tendones y los ligamentos) que rodean la articulación o articulaciones (Aznar Laín \& Webster, s. f., p. 18).

Las personas que realicen este tipo de actividades requieren de paciencia, pues adquirir flexibilidad y elasticidad demanda una inversión de tiempo considerable. Entre las actividades de este grupo, cabe destacar la gimnasia, practicar artes marciales como el karate, el kung-fu, el taekwondo, la capoeira, trabajar pilates, el yoga o cualquier actividad de fuerza o resistencia muscular que ejercite el músculo en la mayor cantidad de movimientos posibles. Estas actividades se pueden desarrollar al aire libre, como lo muestran las fotografias 7 y 8 , o en espacios cerrados como en academias especializadas.

Los individuos que realicen alguna actividad de este grupo, deben tener en cuenta lo siguiente:

- Hay que realizar estiramientos, sin ocasionar dolor y los movimientos deben ser mesurados, evitando tirones o lesiones musculares.

- Se deben realizar estiramientos reiterados (preferiblemente diarios).

- Es bueno realizar calentamiento previo, ya que los músculos y las articulaciones son más flexibles en este estado. 
Fotografías 7 y 8. Práctica de actividades de flexibilidad al aire libre
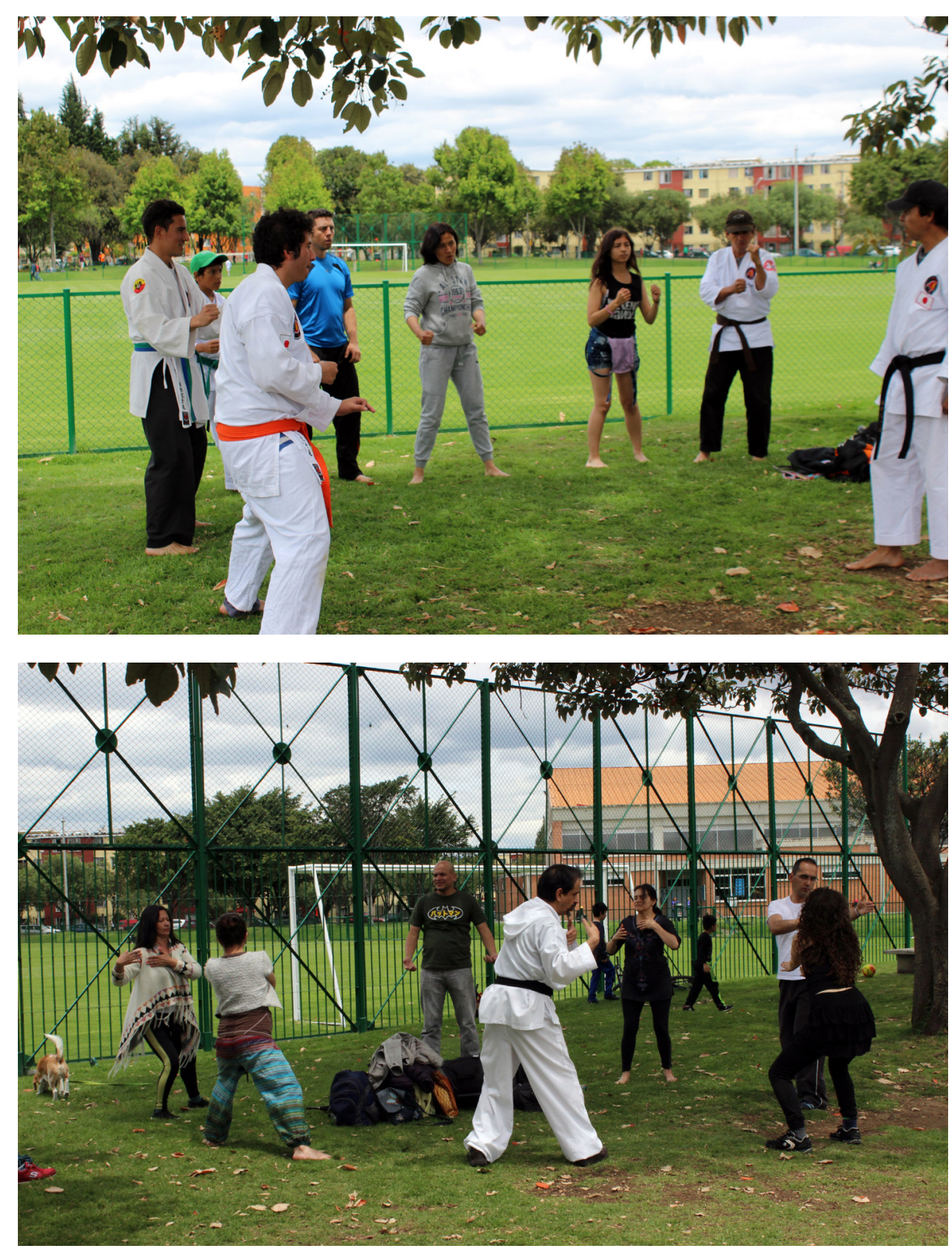

Fuente: archivo del autor. 
Para cualquier actividad que se realice, ya sea de tipo cardiovascular, de fuerza, de resistencia o de flexibilidad se sugiere que su práctica sea regular, en lo posible diaria, con el objetivo de aumentar el efecto beneficioso para la salud. Resulta mejor realizar actividad física moderada todos los días, que actividad física agresiva esporádicamente. La verdad es que no hay un tiempo riguroso establecido para la actividad física. Para los infantes y los adolescentes se sugiere realizar una actividad física mesurada al menos 60 minutos diarios. Se recomienda además, que se incluyan ejercicios encaminados a fortalecer los músculos y a aumentar la flexibilidad. Para aquellos adultos que andan pobres de tiempo, se les sugiere invertir en su salud, al menos 35 minutos de actividad física, 3 o 4 veces a la semana. Otras actividades que se pueden realizar en aras a combatir la vida sedentaria, son las siguientes: desplazamientos diarios a pie hasta y desde el lugar de trabajo, pausas activas cada 45 minutos, caminatas o paseos largos los fines de semana, aumentar los viajes en bicicleta, practicar natación, jugar tenis, voleibol, fútbol o algún deporte que implique ejercicio, como el patinaje. En la fotografía 9 se muestra a unos jóvenes realizando un calentamiento físico previo a la postura de los patines. 
Fotografía 9. Calentamiento físico previo a la postura de patines

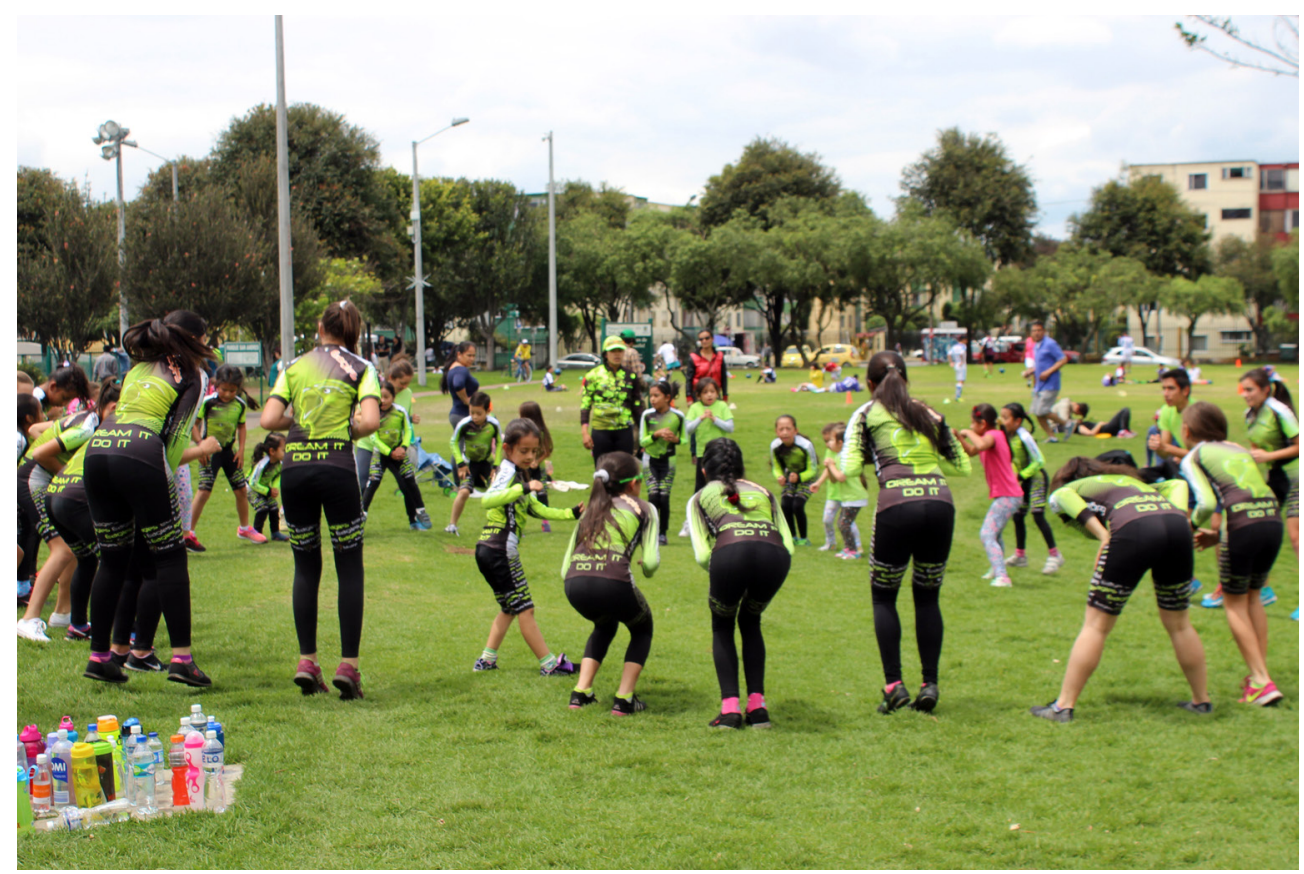

Fuente: archivo del autor.

Son innumerables los beneficios para nuestra salud corporal, mental y hasta social, que conllevan la práctica regular de alguna actividad física; entre los cuales cabe mencionar:

- Desarrollo saludable del sistema cardiorrespiratorio y musculoesquelético.

- Equilibrio calórico.

- Obtención de un peso ideal.

- Prevención de enfermedades cardiovasculares.

- Regulación de la tensión arterial.

- Desarrollo de habilidades sociales.

- Aumento de la autoestima y de la autoimagen. 
- Bienestar mental, aumento del colesterol bueno, reducción y eliminación del colesterol malo y triglicéridos.

- En los jóvenes, una oportunidad para alejarlos de actividades problemáticas, como la participación en bandas criminales y el consumo de sustancias psicotrópicas.

- Reducción del riesgo a desarrollar diabetes, reducción de la ansiedad y el estrés.

- Reducción de la depresión.

- Mejora de la masa ósea, lo cual reduce la probabilidad de padecer osteoporosis en etapas posteriores de la vida; evita los trastornos del sueño.

Como se puede observar, los beneficios que se obtienen al realizar una actividad física son numerosos para nuestro bienestar, y aportan a nuestro cuidado. Por tanto, en una ética del cuidado, es indispensable asumir con responsabilidad y con prontitud la tarea de realizar alguna actividad fisica de forma frecuente y promover en nuestros allegados la cultura del movimiento.

\section{El manejo de las emociones: otro factor importante en nuestro cuidado}

Como lo señala López Blanco, la enfermedad aflora cuando callamos, reprimimos nuestras emociones, cuando llevamos una vida esquizofrénica, inconsciente e inconsecuente, pues pensamos una cosa, decimos otra, sentimos otra y hacemos algo totalmente diferente a lo que pensábamos y sentíamos:

Solemos enfermar cuando nos alejamos de nosotros mismos, cuando nuestras necesidades y deseos van por un lado y nosotros vamos por otro, cuando lo que pensamos, decimos y hacemos no coincide, cuando nos invaden la incoherencia y la 
insatisfacción, cuando dejamos que nuestras emociones circulen sin reconocimiento ni ligazón o incluso cuando las reconocemos, las reprimimos y no las expresamos. (López Blanco, 2008, p. 17)

Un gran porcentaje de nuestras enfermedades son de origen psicosomático y emocional, donde también juegan como causa de nuestros malestares, la herencia, el entorno natural y social, así como el manejo inadecuado de las emociones. De esta manera, la enfermedad emerge como una salida del cuerpo en la búsqueda afanosa del equilibrio y de integridad. El malestar aparece cuando hay algo con lo que no estamos conformes, cuando algo nos incomoda y lo callamos. De ahí el famoso refrán popular, que reza: "el cuerpo grita, lo que la boca calla". Resulta claro, entonces, entender que el ser humano sea una unidad psicosomática, que se ve afectada por su entorno natural, pero también por lo que ocurre en su ambiente familiar, de manera tal que si vivimos en entornos ruidosos y contaminados, estamos expuestos a enfermarnos con mayor regularidad. Igualmente, si nuestro entorno familiar se caracteriza por la presencia de peleas, gritos, reclamos airados, también estaremos más propensos a adquirir enfermedades.

Como se afirmó en capítulos anteriores al hablar de la alteridad, necesitamos de los otros para constituirnos como individuos; necesitamos estímulos sensoriales y afectivos que nos posibiliten configurarnos como personas, puesto que si hay ausencia de afecto y de interacción social, el ser humano tiende a encerrarse, a vivir en soledad, con la particularidad de encontrarse más propenso a sufrir enfermedades. En últimas, se ha comprobado que los individuos necesitamos de abrazos, por ejemplo, para subir nuestro sistema inmunológico ${ }^{1}$.

1 Estudios realizados en la Universidad de Carolina del Norte revelan que cuando otras personas nos tocan o nos abrazan, a cualquier edad, aumentan los niveles sanguíneos de oxitocina, apodada la "hormona del amor", y disminuyen la presión arterial y el ritmo cardiaco. Se puede 
Para la doctora López Blanco los organismos tienen una forma interna de comunicarse con nosotros, y esta se da mediante las sensaciones, las emociones y los síntomas somáticos, por lo que al respecto escribe:

Las sensaciones que proceden del funcionamiento de nuestro organismo nos avisan cuando tenemos hambre, frío, sed, sueño, necesidad de micción o de evacuación intestinal. Las que provienen de las emociones nos informan que estamos experimentando miedo, atracción, alegría, tristeza, sorpresa, ira, vergüenza, envidia, celos, orgullo y amor, entre otras posibles. Por su parte, los síntomas somáticos expresan algún tipo de conflicto, nos convocan a tomar contacto con él y nos reclaman la realización de un cambio. (López Blanco, 2008, p. 47)

Efectivamente, los síntomas somáticos o las dolencias afloran cuando hay una especie de conflicto, cuando no podemos afrontar armónicamente nuestras relaciones interpersonales, ya sea con nuestra pareja, nuestra familia, nuestros amigos o con los integrantes de la comunidad de la cual formamos parte. Cuando no hay equilibrio y armonía en nuestras relaciones, aparecen muchas veces la frustración, el miedo y la culpa, y si a esto se le agrega la renuncia al alimento y los conflictos se prolongan, se puede caer en enfermedades crónicas, en dependencia de fármacos y, en últimas, hasta en la misma muerte.

Para la doctora López Blanco,

[...] las emociones son fenómenos que surgen como reacción a las evaluaciones automáticas que hacemos de aquello que nos acontece, es un estado que sobreviene de forma súbita, con

consultar al respecto en http://www.muyinteresante.es/ciencia/articulo/ ipor-que-necesitamos-los-abrazos 
diferente grado de fuerza y duración según cuál sea el motivo que lo provocó. (2008, p. 77).

En este sentido, puede haber emociones buenas y gratificantes como el amor, la alegría, el optimismo, pero también se pueden presentar emociones negativas, como la ira, la tristeza, la culpa, la envidia, el odio y el rencor, entre otras.

Tanto las emociones positivas como las negativas hacen parte del ser humano, y tienen una función comunicativa, que termina siendo esencial para regular nuestra interacción social. No se trata de reprimir las emociones sino de encauzarlas asertivamente, de manera que se potencien las emociones positivas, y se aprenda a manejar las negativas, puesto que, si no hay control sobre ellas, podemos enfermarnos o herir tanto mental como físicamente a nuestros congéneres. A manera de ejemplo, la ira aparece regularmente cuando hay episodios de frustración, o cuando nos han lastimado o nos han traicionado; al experimentarla, la sangre se encamina con fuerza y prontitud a los lugares donde se le requiere, que comúnmente es al cerebro para activar el pensamiento, y a los músculos para posibilitar una acción violenta. El ritmo cardiaco y el respiratorio se intensifican, el proceso digestivo se interrumpe, el hígado envía a la sangre los hidratos de carbono almacenados, colmándolos de azúcar. Este incremento de glucosa aumenta la eficacia muscular y proporciona grandes cantidades de energía prestos para la lucha que se presente, los cabellos se erizan, el sudor se presenta constantemente y la mente se llena de pensamientos negativos, y deseos de acabar con el otro que produjo intensa cólera.

La doctora López Blanco nos indica que se debe controlar la ira, puesto que, de no hacerlo, se pueden provocar enfermedades gravísimas:

La ira puede ser muy peligrosa para nosotros mismos y para nuestro entorno si no aprendemos a controlarla y encauzarla. 
En su forma explosiva, se presenta con conductas verbales o físicamente agresivas que pueden producir respecto de nuestra salud, por ejemplo, hipertensión arterial, infarto de miocardio o accidentes cerebrovasculares. En su forma implosiva, puede provocar, entre otros síntomas, gastritis o úlcera estomacal. (López Blanco, 2008, p. 83)

Cuando la rabia se prolonga en el tiempo permite que eclosione el resentimiento y que nazcan conductas vengativas que para nada aportan al bienestar individual, sino que, por el contrario, facilitan que se intensifique el dolor, el malestar subjetivo y que se menoscaben las relaciones interpersonales.

Otras emociones negativas, como la tristeza, permiten desencadenar una serie de actitudes poco beneficiosas para la salud, tales como la depresión, la fatiga, la falta de concentración, la pérdida del apetito, el trastorno del sueño, la desesperanza, la disminución del deseo sexual y los sentimientos de culpa. Ante este fenómeno urge de forma apremiante detectar esas emociones negativas cuando estén aflorando y encauzarlas, para que no se despierten los sentimientos de aversión, odio y rencor que para nada contribuyen al cultivo de la salud emocional duradera y equilibrada. Adicionalmente, está comprobado que los estados emocionales negativos pueden prolongar infecciones, retardar la cicatrización de heridas y hacernos más vulnerables a desarrollar o contraer enfermedades como el asma, la artritis, los dolores de cabeza, las úlceras estomacales y los problemas cardíacos (López Blanco, 2008, p. 91).

Para finalizar este apartado, es necesario enfatizar en la necesidad de cultivar nuestra autoestima, sintiéndonos bien con nosotros mismos, con lo que hacemos, disfrutando cada momento que la vida nos regala, y compartiendo momentos agradables con nuestros seres queridos. Vivamos entonces proponiéndonos metas, esforcémonos por alcanzarlas, reconozcamos nuestras debilidades, mejoremos y 
potenciemos nuestras habilidades; que nuestra vida tenga siempre un propósito a la vista y un sinnúmero de motivos para existir.

\section{El alimento: un asunto vital en nuestro cuidado}

Ya lo decía Hipócrates, "que tu medicina sea tu alimento" y tenía mucha razón. De una u otra forma somos los que comemos; si ingerimos comida con pocos nutrientes, vamos a estar como "zombis" y sin energía, por lo que es necesario prestar mucha atención a lo que consumimos, a los tiempos y lugares en que lo realizamos, a las personas con las que compartimos y a los estándares de higiene aplicados para cubrir esta necesidad, puesto que estos aspectos terminan siendo una cuestión de relevancia para nuestro cuidado y bienestar individual.

La alimentación es una cuestión vital, es una necesidad corporal y una tremenda fuente de disfrute. Antaño se valoraba la hora de comer, puesto que este espacio era casi sagrado y congregaba a la familia. De hecho, todavía se conservan algunos espacios de esta índole, sobre todo con motivos de festividades, celebraciones y circunstancias especiales donde se comparte en familia. En la actualidad, se le ha dado primacía a la jornada laboral y el alimento ha pasado a un segundo plano; se come cualquier cosa, algo rápido, un sándwich, una hamburguesa, o algo que aminore el hambre para seguir laborando.

La nutricionista Susana Zurschmitten en su libro La dieta inteligente, citada por López Blanco, nos ofrece las bondades de alimentarnos bien. $\mathrm{Al}$ respecto, expresa lo siguiente:

A través de la alimentación podemos ordenar el funcionamiento orgánico, desintoxicar el organismo, mejorar la circulación, la nutrición celular, el sistema inmunológico y el funcionamiento del sistema nervioso. Este orden se reflejará también en un mayor equilibrio emocional y mental. De esta forma se 
va preparando el terreno para el desarrollo integral del ser humano. (López Blanco, 2008, p. 112)

Una alimentación adecuada aporta miles de beneficios para nuestros organismos, contribuye con la energía y los nutrientes que regularmente demanda nuestro cuerpo para cumplir sus funciones vitales, como la circulación de la sangre, la respiración, la temperatura corporal, la función renal y el tono nervioso; y para desarrollar nuestras actividades habituales como caminar, hacer aseo, jugar, estudiar y trabajar, entre otras.

La alimentación nos proporciona lo necesario para nuestra supervivencia, y entre los nutrientes que nos regala podemos encontrar los hidratos de carbono, las proteínas, los lípidos o grasas, las vitaminas y las sales minerales. Asimismo, alimentarnos bien coadyuva en el mantenimiento óptimo de nuestro sistema inmunológico, ideal a la hora de repeler infecciones y enfermedades.

Se recomienda entonces que la alimentación sea lo más variada posible, buscando el equilibrio y sin excederse en algún grupo de alimentos, puesto que el cuerpo se puede resentir. $\mathrm{Al}$ respecto López Blanco (2008) afirma que la energía necesita repartirse de manera proporcionada entre los distintos nutrientes, por lo que es conveniente que el 12-15\% del valor calórico total de una dieta proceda de las proteínas, el 30-33 \% de las grasas y el 50-55 \% de los hidratos de carbono (p. 113).

En esta dieta, López Blanco sugiere que las proteínas sean la octava parte de nuestra alimentación, por lo que es clave enfatizar sobretodo en el hecho de que las proteínas de origen animal, consumidas en exceso, pueden ocasionar enfermedades de tipo cardiovascular. Las proteínas están presentes en los alimentos que proceden del reino animal y vegetal. Del reino animal, cabe mencionar que son ricas en fuentes proteicas las carnes, los huevos, la leche y sus derivados; y del reino vegetal aportan cantidades proteicas, la soja, los cereales (arroz, mijo, avena, trigo, cebada y 
maíz), las legumbres (lentejas, fríjoles y garbanzos), las semillas (sésamo) y los frutos secos (avellanas, almendras, nueces, maní). Lo que pasa con las proteínas de origen vegetal, es que al consumirlas solas, estas carecen de algún aminoácido esencial; sin embargo, bien combinadas logran aportar las proteínas suficientes para nuestro sustento diario. Un derivado del trigo, el gluten, termina siendo una buena fuente proteica, sobre todo para los que han renunciado a consumir algún nutriente de origen animal, no obstante, algunas personas no lo pueden consumir, porque son alérgicas a la ingesta del mismo.

Otro de los elementos que sirve para una dieta equilibrada procede de las grasas. Estas son compuestos orgánicos que se establecen gracias a la simbiosis de carbono, hidrógeno y oxígeno y son la fuente más condensada de energía en los alimentos. Las grasas sirven como canales para las vitaminas A, D, E y K y, además, promueven el surgimiento de varias hormonas. Algunas grasas saludables se pueden encontrar o extraer de la oliva, el girasol, el maíz, la soja, el maní y el aguacate. Las grasas que provienen del mundo animal, como las derivadas del ganado ovino y vacuno, pueden aumentar el colesterol malo en la sangre y posibilitar el anidamiento de enfermedades cancerígenas.

López Blanco sugiere que se consuma una gran cantidad de hidratos de carbono en nuestra dieta diaria (más del $50 \%$ de nuestra dieta); ahora, estos hidratos de carbono también son llamados carbohidratos o sustancias conformadas por carbono, oxígeno e hidrógeno, los cuales contribuyen con energía al organismo, de forma casi instantánea y significativa. Algunos equiparan los carbohidratos con el combustible, pues inyectan una energía considerable a los organismos. Los hidratos de carbono, pueden ser simples, como el azúcar y la miel, o compuestos, como los cereales y las legumbres.

Los carbohidratos regulan la tensión arterial, la actividad neuronal, el correcto funcionamiento del sistema digestivo y ayudan 
en la conservación de la temperatura corporal. En el grupo de los hidratos de carbono se pueden encontrar las frutas y las verduras, las cuales también aportan vitaminas y minerales a nuestro organismo. Asimismo, los carbohidratos nos suministran la glucosa, la cual es indispensable para nuestro rendimiento. Sin embargo, se nos ha vendido la idea y hasta se ha creado un mito en torno a los carbohidratos, aduciendo que engordan, que son tóxicos, y que no ayudan con la dieta. Lo que sí es cierto es que si consumimos más calorías de las que necesitamos a diario, estas se van acumulando en nuestro organismo, con el peligro de alterar la salud.

Ahora bien, existen algunos hidratos de carbono que ofrecen calorías vacías, que poco aportan a la salud, y, por el contrario, son perjudiciales para nuestro organismo como las bebidas gaseosas, las bebidas azucaradas y las bebidas energizantes. Otros hidratos vacíos son los dulces elaborados a partir de azúcares refinados, como la mayoría de los chocolates, bombones y confites, que efectivamente van en detrimento de la salud y que coadyuvan en la aparición de enfermedades relacionadas con la obesidad.

Retomando las verduras, cabe enfatizar en el hecho de que estas aportan enzimas nutritivas y minerales al organismo, al igual que enzimas antioxidantes que demoran el envejecimiento de las células, aportan buena fibra y ayudan a facilitar la digestión. Además, participan en el suministro de potasio, ayudan a eliminar líquidos, a mantener el peso y a luchar contra la obesidad.

El consumo de verduras y hortalizas ayuda a regular el nivel de grasa presente en la sangre, sirve para prevenir la arterosclerosis y mejorar las funciones del sistema circulatorio. Por ejemplo, el consumo de la zanahoria mejora la nutrición de los tejidos y revitaliza la piel, renovando su aspecto. Igualmente, el consumo de espinacas alimenta nuestro organismo proporcionándole agua, potasio, calcio, magnesio, cobre, ácido fólico y vitaminas B1, C, A, y E. En las fotografias 10 y 11 se presentan algunas de los vegetales que hacen parte de la habitual dieta de los colombianos. 
Fotografías 10 y 11. Vegetales de consumo habitual
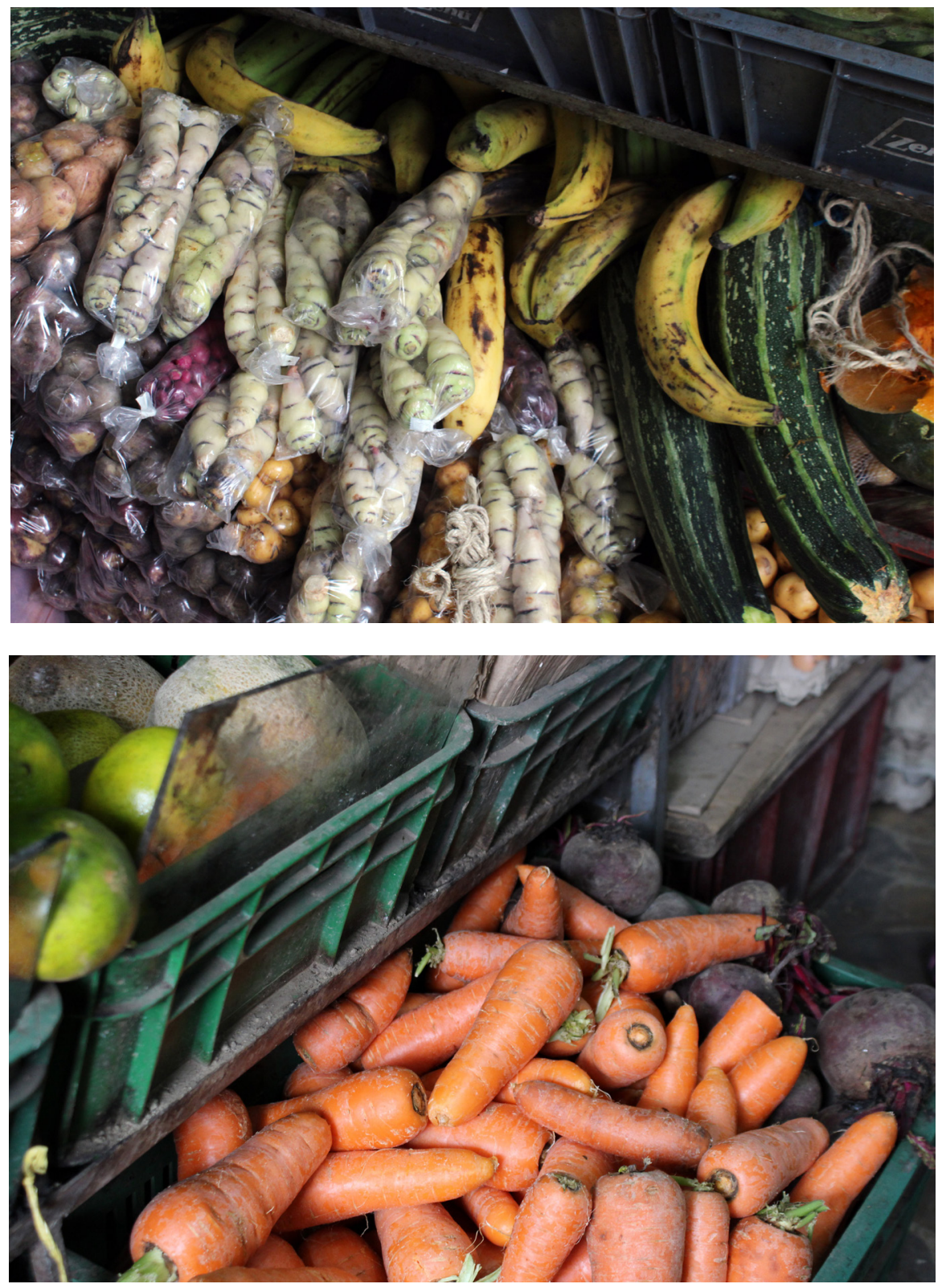

Fuente: archivo del autor. 
En cuanto a las frutas, estas aportan para nuestro organismo fibra, minerales, vitaminas, antioxidantes, hidratan la piel, ayudan a un correcto funcionamiento del sistema digestivo, son diuréticas, depurativas y alcalinizantes. Algunos expertos en dietas y nutrición sugieren como cantidad mínima el consumo de 400 g diarios de fruta fresca. Algunos difieren de este gramaje, pero igual, recomiendan consumir entre 3 y 5 porciones diarias de fruta; se deben consumir antes de las comidas, con el objetivo de mejorar la digestión. Como lo muestran las fotografías 12 y 13, Colombia - país privilegiado por su posición geográfica y por la variedad de pisos térmicos-, produce más de treinta clases de frutas, las cuales son, en su mayoría, asequibles a las personas.

Fotografías 12 y 13. Algunas frutas producidas en Colombia

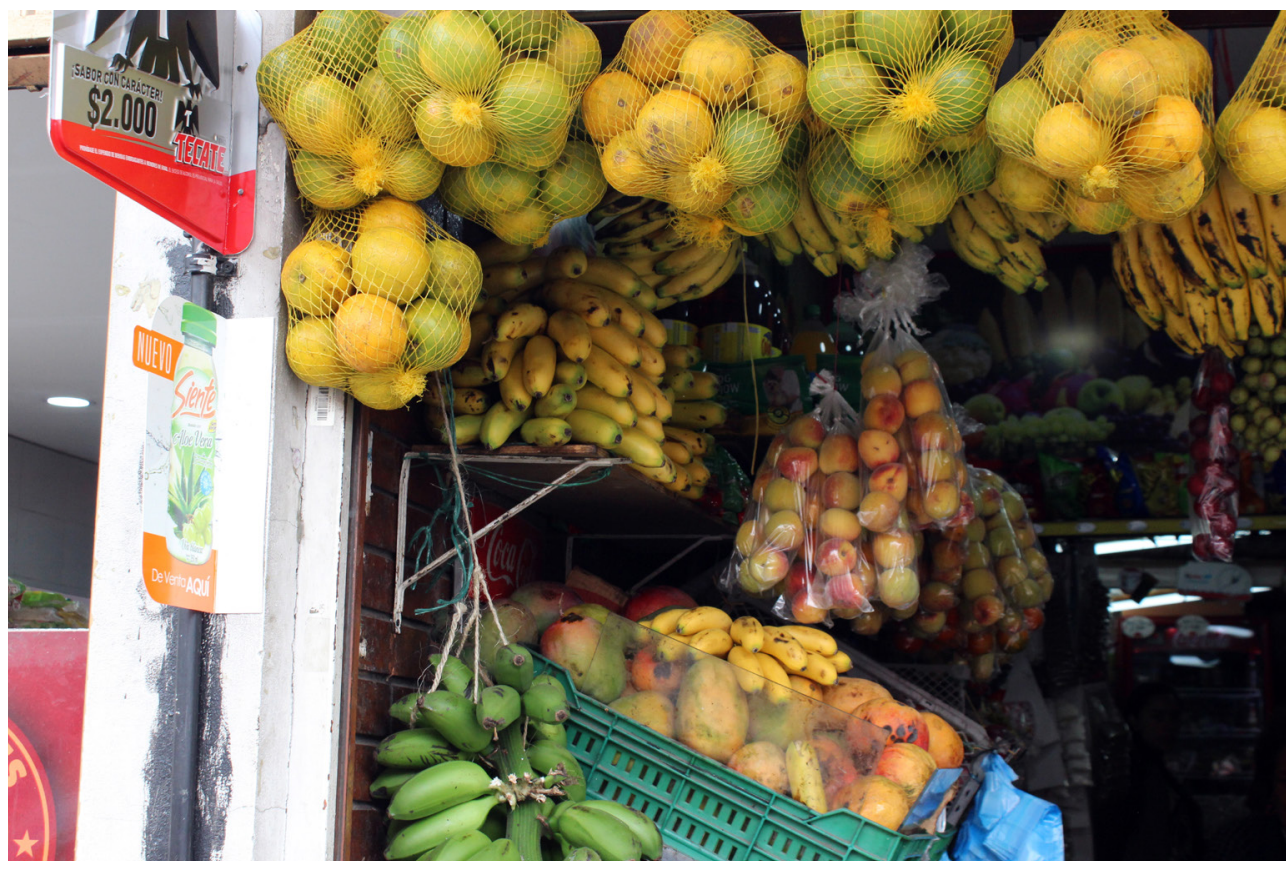




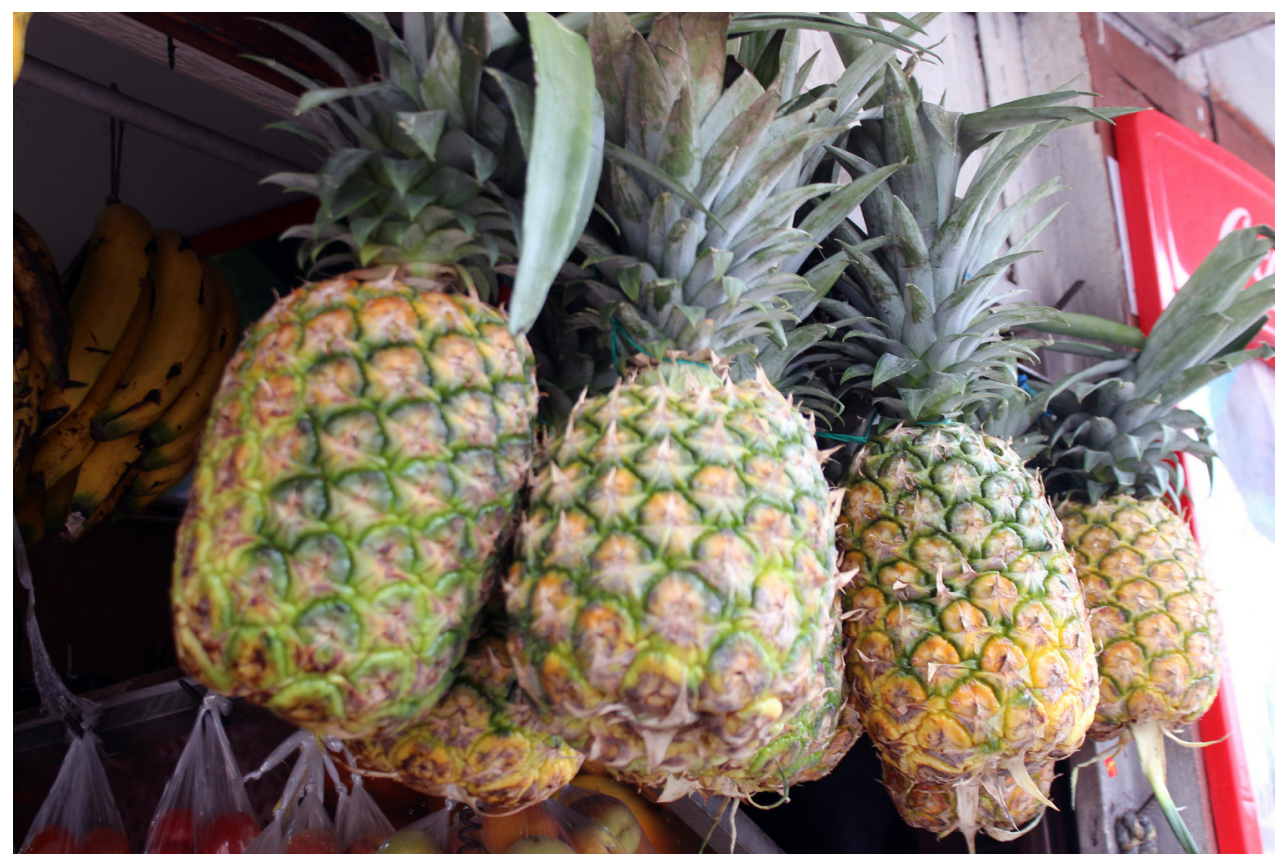

Fuente: archivo del autor.

Cabe resaltar que las frutas como la piña y la papaya son de gran beneficio para la salud. La piña contiene bromelaína que sirve para digerir las proteínas en el estómago, por lo cual ayuda en el proceso de digestión; así como, a suplir la ausencia de jugo gástrico. Alivia el estreñimiento y los gases intestinales, abre el apetito y expulsa los parásitos presentes en el sistema digestivo.

Por su parte, la papaya es rica en una enzima denominada papaína, que también ayuda a digerir las proteínas del estómago, aporta fibra en gran cantidad y ayuda al tratamiento tanto del estreñimiento como de la diarrea. La papaya contiene betacarotenos que, a su vez, sirven como antioxidantes (fotografía 14). 
Fotografia 14. Papayas

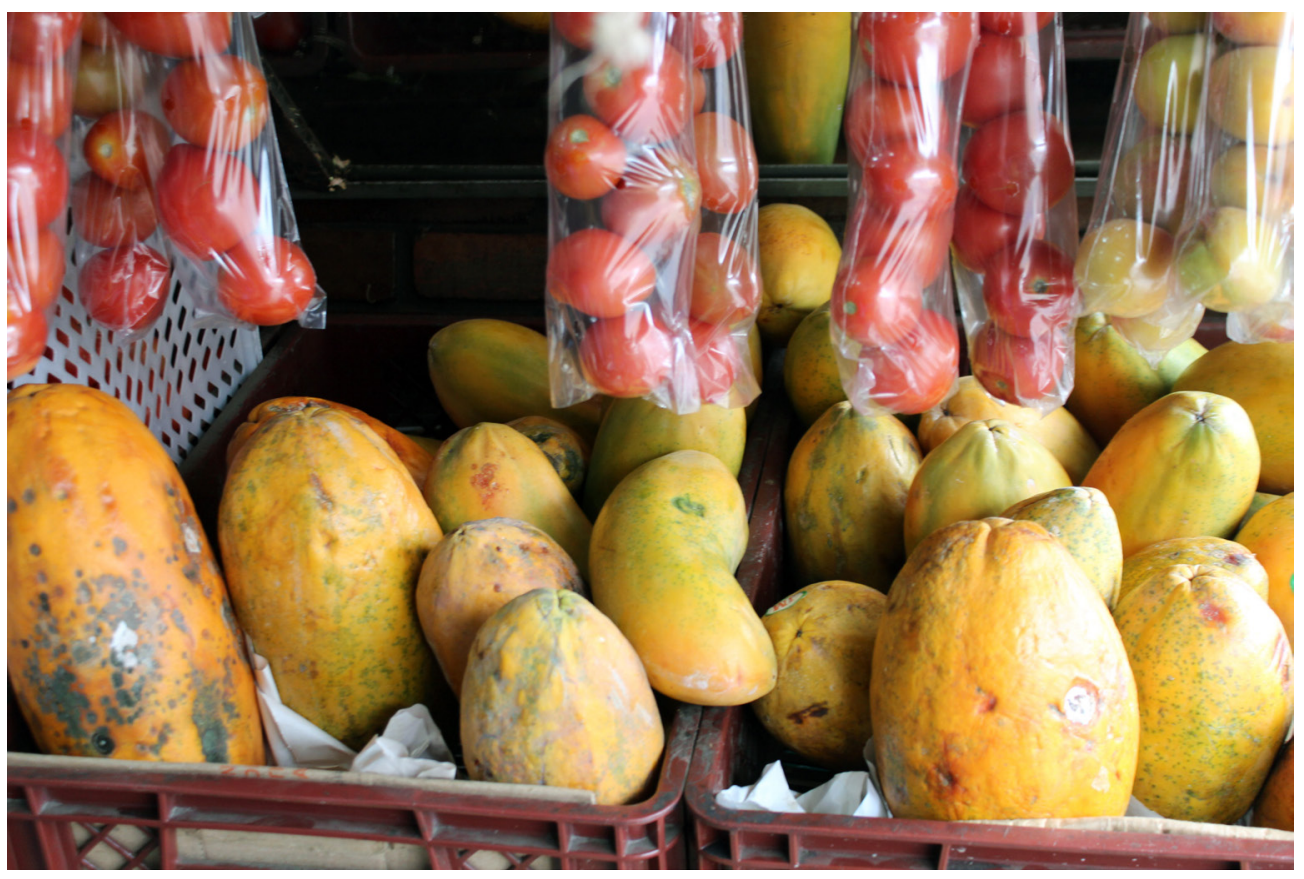

Fuente: archivo del autor.

Luisa Martín, en su libro Buenas digestiones (2010) propone algunas pautas que buscan afianzar la búsqueda de un estado de bienestar duradero en los seres humanos, por lo que cabe enunciar las siguientes:

- Evitar el consumo excesivo de café, pues este puede ser adictivo y causar somnolencia.

- Evitar la toma de fármacos antiinflamatorios que suelen tener consecuencias secundarias.

- Vivir más pausado ayuda a evitar el estrés y a saber degustar los alimentos. 
- Practicar técnicas de relajación como el yoga, el taichí, y el reiki pueden ayudar a reducir y eliminar el estrés y el exceso de acidez gástrica.

- Tomar baños de sol es saludable en horarios adecuados, antes de las 10:00 de la mañana y después de las 4:00 de la tarde.

- Evitar el consumo excesivo de carnes rojas.

- Reducir al mínimo el consumo de sal, se sugieren 6 gramos al día.

- Consumir mucha fibra natural, como el arroz integral, la avena y pan integral.

- Consumir leche deslactosada o, en su defecto, leche de soya.

- Eliminar el consumo de embutidos, pues contribuyen con gran cantidad de sal y condimentos dañinos para el organismo.

- Pocas grasas, pues las margarinas no son amigables con el hígado.

- Masticar lentamente los alimentos.

- Empezar las comidas con un plato de vegetales crudos o frutas frescas.

- Evitar tomar líquidos, como jugos o bebidas, encima de los alimentos, puesto que al mezclarse con los jugos gástricos dificultan la digestión.

- Evitar los alimentos irritantes de la mucosa como el alcohol, los picantes y los guisantes.

- Caminar y realizar actividad física estimula el movimiento de los intestinos y relaja el sistema nervioso.

- Dormir bien, en un ambiente adecuado y entre 6 a 8 horas diarias.

- La alimentación debe estar exenta de dulce, azúcar de cualquier clase, pasteles, golosinas y harinas refinadas (Martín, 2010, pp. 120-131). 
Finalmente, cabe hacer hincapié en el hecho de que todo en el organismo está interconectado. Es por ello que nuestro sistema digestivo es muy susceptible a las emociones y los estados de ansiedad, estrés y nerviosismo. Si comemos velozmente y no masticamos bien los alimentos, el aparato digestivo se lamentará seguramente. El estrés produce cortisol que, a su vez, bloquea los órganos digestivos, ocasiona que el estómago fabrique menos ácido clorhídrico y que los intestinos se muevan lentamente, posibilitando la aparición del estreñimiento, tan frecuente en nuestro tiempo.

López Blanco nos recomienda también sacar el tiempo necesario para alimentarnos bien. $\mathrm{Al}$ respecto escribe:

Los malos hábitos alimenticios pueden provocar un aumento en la ingesta de aire y provocar una sensación de distensión, eructos frecuentes, gases, dolores abdominales, sensación de leve ahogo e incluso la de tener un cuerpo extraño en la garganta. Para evitar esto, es recomendable que incorporemos el hábito de sentarnos a la mesa con tiempo y masticar bien los alimentos. (López Blanco, 2008, p. 114)

Recapitulando, se puede afirmar que es preciso y necesario para el bienestar de los individuos realizar actividad física frecuente, encauzar las emociones negativas y expresarlas de forma asertiva, cultivar las emociones positivas, llevar a cabo una dieta equilibrada que sea variada, nutritiva y que sirva como medicina del cuerpo, evitar la ingesta de pastillas que, regularmente, producen efectos colaterales para la salud. 


\section{Conclusiones}

H 1 hombre contemporáneo es un individuo pusilánime, sin un que se deja impactar fácilmente por los espectáculos y el mundo de la publicidad. Es un ser que hace parte del engranaje económico, maquinizándose, con una vida programada que se prolonga en las redes sociales, haciendo parte de una sociedad interconectada, etérea y paradójicamente solitaria.

Este individuo camina en una franja delgada entre una sociedad del consumo y la sociedad del espectáculo, que por un lado trabaja para consumir y responder por lo adquirido como fruto de la publicidad, y por el otro, obnubilado por aquel mundo vertiginoso que no deja pensar, que enceguece con las luces del espectáculo y del mundo hedonista, que impide crecer integralmente como persona.

El hombre de hoy ha perdido su interioridad convirtiéndose en receptor pasivo de información que lo fatiga y lo abruma. Es víctima de un modelo antropológico visto desde la informática que le impide encontrarse con los otros. Así, termina siendo un número más en el Facebook, que comunica pensamientos carentes de reflexión, insignificantes y triviales, donde importa más la imagen, lo que se siente que lo que se piensa, terminando reducido muchas veces a la imagen que publica.

Frente a ese hombre cegado por el consumo, el nihilismo, la indiferencia, el desgano y la apatía se ofrece una propuesta basada 
en el cuidado. Donde los individuos se esfuercen por construir sociedades solidarias y cooperativas, donde se posibiliten espacios de encuentro interpersonal y se propicie el cuidado por el planeta como lugar donde se puedan fraguar los sueños y vivir dignamente.

Ante la mezquindad con el tiempo que caracteriza el mundo de hoy, es imperioso hacer un uso adecuado del mismo, que se invierta en la salud propia y en el cuidado de los seres queridos y donde se tome conciencia de que hay un momento para todo y que, si bien el trabajo es necsario y se dignifica la vida con él, este no debe convertirse en una interferencia para el bienestar de la persona y de la familia.

También se requiere dejar un tiempo para reflexionar sobre nuestra vida, sobre nuestras acciones y sobre el futuro de nuestros proyectos. Debe haber un tiempo para descansar y recuperar fuerzas, para realizar alguna actividad física, para la recreación y para saber alimentarnos humanamente. Igualmente, el hombre está llamado a manejar adecuadamente sus emociones, puesto que de no hacerlo, se podrán desencadenar consecuencias nefastas que van en contra de la misma persona.

En una antropología del cuidado se promueve una cultura cooperativista, se denuncia el paradigma actual donde se da origen al nuevo narciso y se deifica al individuo, al punto de promover una egolatría sin parangón alguno. No se puede negar que los individuos se constituyen como animales sociales y en esa medida dependen de los otros, de su familia, los amigos, la escuela y de la sociedad en general.

El conocimiento y las actuaciones humanas deben promover la convivencia y el progreso en general, donde se posibilite la perfectibilidad humana, se aprenda de los errores del pasado y se trabaje por una educación desde y para el cuidado, una educación que busque el desarrollo de las potencialidades humanas en favor del bienestar integral humano. 
Desde una antropología del cuidado no basta con denunciar los vejámenes de las guerras, ni de evitar todo aquello que conlleve a suscitar la envidia y los celos, sino que es necesario promover el trabajo mutuo, sin importar la ubicación geográfica, que se encaucen los esfuerzos individuales para buscar fines sociales, que se trabaje en pro de la humanidad y no de los intereses mezquinos de un grupo en particular; nuestras prácticas diarias deben aproximarse al cultivo refinado de la filantropía, pues, si se ama a los individuos sin distinción alguna, se logra trabajar en pro de toda la humanidad, buscando siempre mejorar aquellas situaciones de inequidad. Algo así como una antropología del cuidado a nivel planetario.

Igualmente, esta propuesta antropológica basada en el cuidado busca configurarse en una apuesta por una vida sana y saludable, donde se unan esfuerzos para contribuir en la formación integral de los estudiantes haciendo énfasis en los componentes reflexivos, críticos y creativos que aporten a la solución de aquellos problemas que emergen del contexto colombiano y mundial. Con esta indagación no solo se pretendió la reflexión, sino la transformación de la acción educativa.

Este fruto de aportes de autores reconocidos y de la cotidianidad, se erige como una crítica a ese estilo de vida consumista y narcisista que se está promoviendo como estereotipo desde los medios de información y que es patrocinado por grandes emporios económicos, como estrategia de adormecimiento colectivo. Se busca ofrecer una visión alternativa del mundo, donde se reconozca al individuo como un sujeto histórico, ético, creativo y crítico y que asume su rol protagónico en los procesos de transformación de su realidad actual.

Se espera que las reflexiones abordadas en este libro aporten, desde una perspectiva del cuidado, a la constitución de ciudadanía, cultura y democracia, dentro del proceso pedagógico 
contemporáneo en la Universidad y de otros centros educativos a nivel nacional e internacional.

Por último, estoy seguro que aunque falta mucho por reflexionar, desde la antropología del cuidado se ofrecen aportes significativos, que ayudarán para que muchos niños y jóvenes, especialmente, sean conscientes del papel protagónico que deben desempeñar en la construcción de una sociedad incluyente, solidaria, humana, cooperativa y más sana y saludable. 


\section{Bibliografia}

Aristóteles. (2015). La ética a Nicómaco. Montevideo: Uruguay Piensa. Recuperado de http://www.uruguaypiensa.org.uy/imgnoticias/650.pdf

Aznar Laín, S. \& Webster, T. (s. f.). Actividad fisica y salud en la infancia y la adolescencia. Madrid: Grafo.

Barylko, J. (2012). Los múltiples sentidos de la vida. Buenos Aires: Ediciones B.

Bauman, Z. (2003). Modernidad líquida. Madrid: Fondo de Cultura Económica de España.

CEPAL (15 de abril de 2016). CEPAL. Recuperado de http://www.cepal. org/es/comunicados/la-concentracion-ingreso-la-riqueza-esta-corazon-la-desigualdad-la-region-cepal-oxfam

Comins Mingol, I. (2009). Filosofia del cuidar. Barcelona: Icaria.

Gruz Molina, M. (2003). Experiencias educativas para la promoción de la saludy la prevención. Barcelona: Laertes.

Cubides Cipagauta, H. (2006). Foucault y el sujeto político: Ética del cuidado de sí. Bogotá: Siglo del Hombre Editores.

Enlace. (1 de agosto de 2016). Enlace México. Recuperado de http:/ / www.enlacemexico.info/index.php/actualidad / ecologia/1128-el-agua-el-precio-a-pagar-de-una-sociedad-indiferente

Foucault, M. (12 de julio de 2016). La ética del cuidado de sí mismo. Recuperado de Topologik.net: http://www.topologik.net/Michel_Foucault.htm

Foucault, M. (1987). Historia de la sexualidad Vol. 3: La inquietud de sí. Madrid: Siglo XXI. 
Lipovetski, G. (1983). La era del vacío: ensayos sobre el individualismo contemporáneo. Madrid: Anagrama.

López Blanco, A. (2008). ¿Por qué nos enfermamos? Buenos Aires: Paidós.

Maffesoli, M. (2009). El tiempo de las tribus. Ciudad de México: Siglo XXI.

Martín, L. (2010). Buenas digestiones. Bogotá: Stilo Impresores.

Papa Francisco. (2015). Carta encíclica Laudato Sí. Bogotá: San Pablo.

Redeker, R. (2014). Egobody: la fábrica del hombre nuevo. Bogotá: Fondo de Cultura Económica.

Rojas Osorio, G. (2010). Filosofia de la educación: de los griegos a la tardomodernidad. Medellín: Universidad de Antioquia.

Sánchez Bañuelos, F. (1996). La actividad fisica orientada hacia la salud. Madrid: Biblioteca Nueva.

Sartre, J. P. (1954). El ser y la nada. Madrid: Losada.

Vardey, L. (2012). Ser generosos: el arte de vivir correctamente. Buenos Aires: Ediciones B.

Varios, A. (15 de noviembre de 2016a). Etimologías de Chile. Recuperado de http:/ / etimologias.dechile.net/?antropolo.gico

Varios, A. (15 de noviembre de 2016b). Etimologías de Chile. Recuperado de http:/ / etimologias.dechile.net/?e.tica

Varios, A. (24 de julio de 2016c). Intergovernmental panel on climate change. Recuperado de http://www.ipcc.ch/pdf/assessment-report/ar5/syr/ AR5_SYR_FINAL_SPM_es.pdf 


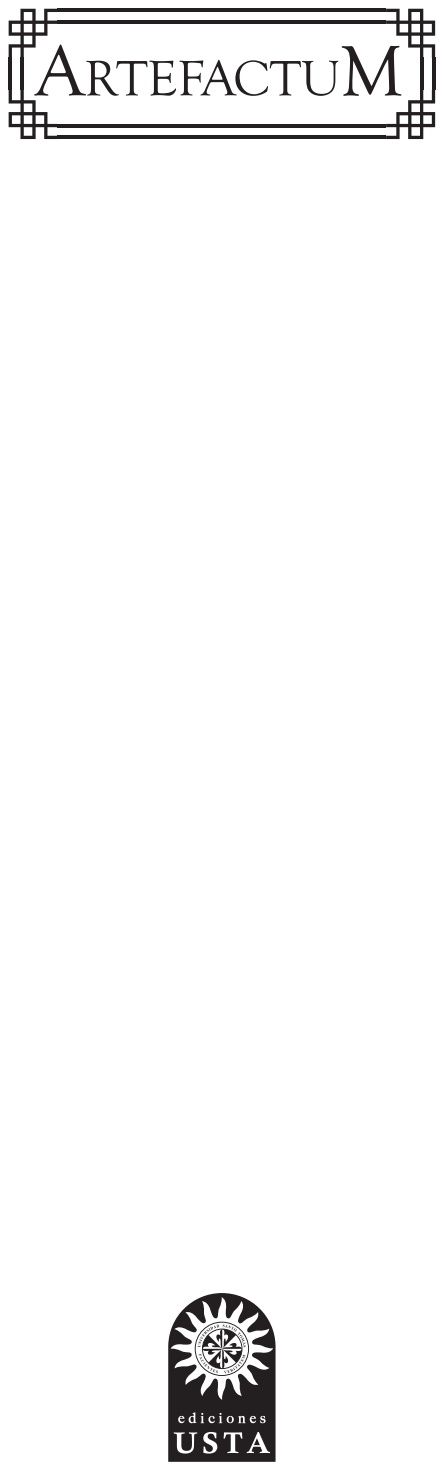

Esta obra se editó en Ediciones USTA,

Departamento Editorial de la Universidad Santo Tomás. Se usó papel propalcote de 300 gramos para la carátula y papel bond beige de 75 gramos para páginas internas.

Tipografía de la familia Baskerville 2017. 
- $\mathrm{n}$ el presente libro se realiza, una exposición acerca de la concepción actual del hombre que cae en una especie de individualismo extremo y deja en el olvido valores como la solidaridad, la empatía, el altruismo y la responsabilidad para consigo mismo y con el planeta. Luego, los esfuerzos se detendrán en una antropología que propuso el pensador francés Michel Foucault y que gravita en torno al cuidado de sí.

La obra está planteada para desarrollarse en cuatro momentos bien delimitados. En un primer momento se presenta una propuesta acerca de la concepción actual del hombre, destacando el excesivo individualismo en el que se encuentra inmerso, la influencia de los medios de comunicación, el consumo desmedido, la sociedad del espectáculo, el reemplazo de la ética por una estética y la pérdida de identidad, entre otros tópicos. En segundo lugar, se presenta la apuesta del autor, que guarda una estrecha relación con la antropología del cuidado, desde una mirada de Michel Foucault y Comins Mingol. En tercer lugar, se exponen algunas prácticas que han llevado al deterioro gradual de nuestro planeta, y que coadyuvan en el detrimento de la salud y el bienestar de las personas. En el último apartado, se traen a colación algunas recomendaciones que podrían contribuir a la construcción de una antropología del cuidado, como un ethos de vida sana y saludable 